\title{
BIOMEMS AND NANOTECHNOLOGY-BASED APPROACHES FOR RAPID DETECTION OF BIOLOGICAL ENTITIES
}

\author{
SHANTANU BHATTACHARYA ${ }^{1,2}$, JAESUNG JANG $^{1,2}$, LIJU YANG $^{4}$, \\ DEMIR AKIN ${ }^{1,3}$ and RASHID BASHIR ${ }^{1,2,3,5}$ \\ ${ }^{1}$ Birck Nanotechnology Center \\ ${ }^{2}$ School of Electrical and Computer Engineering \\ ${ }^{3}$ Weldon School of Biomedical Engineering \\ Purdue University \\ West Lafayette, IN 47907 \\ ${ }^{4}$ Biomanufacturing Research Institute \& Technology Enterprise (BRITE) \\ Department of Chemistry \\ North Carolina Central University \\ Durham, NC
}

Accepted for Publication February 8, 2007

\begin{abstract}
In recent years, the areas of Bio-Microelectromechanical Systems (BioMEMS) and nanotechnology have gained a high level of prominence and have become almost inseparable with biological applications including detection, diagnostics, therapeutics and tissue engineering. This article reviews some of the current state-of-the-art interdisciplinary research from these fields, especially focusing on rapid detection of pathogens and microorganisms, a critical area of importance to food safety, clinical diagnostics and related applications.
\end{abstract}

\section{PRACTICAL APPLICATIONS}

Food microbiology has been an inseparable part of food quality monitoring and control. However, all the diagnostic techniques in a microbiology laboratory are time and labor intensive. As on date the principal requirement of the food industry is the fast, accurate and easy to handle devices which have the potential of point of care detection. A lot of research demonstrating a high level of synergism between microbiology, nanotechnology and microelectronic processing has been directed towards the rapid detection and

${ }^{5}$ Corresponding author. TEL: 765-496-6229; FAX: 765-494-6441; EMAIL: bashir@purdue.edu

Journal of Rapid Methods \& Automation in Microbiology 15 (2007) 1-32. All Rights Reserved. (C) 2007, The Author(s) 
analysis of food borne pathogens in the last decade. Devices like "petri-dish on a chip" can perform high speed fully automated culture, growth and analysis of food samples with trace quantities of pathogenic cells. Impedance microbiology can be performed on a chip scale to investigate cell viability and growth with enhanced sensitivity. DNA micro-arrays is another area which is an offshoot of this synergistic research and is widely used by molecular biology laboratories for diagnostic research. Micro-cantilevers, which are diving board type structures at the microscopic length scale are successfully can be used for monitoring the presence of pathogenic cells and viruses within the local environment of a food processing or packaging center. The article reviews some of the most state of the art research in this direction.

\section{INTRODUCTION}

During the last several decades, micro-system research mainly addressed electromechanical systems (Trimmer 1997) and in recent years the focus has shifted to Bio-Microelectromechanical Systems (BioMEMS) and Nanotechnology. This shift is driven primarily by the potential applications of the micro-systems to chemistry, biology and medicine (Nguyen and Wereley 2002; Bashir 2004). In fact, a combination of BioMEMS and nanotechnology has made possible the realization of physical systems at scales and dimensions similar to biological entities such as bacterial and mammalian cells, viruses, spores, etc., and this has resulted in the development of a variety of diagnostic and therapeutic applications of intelligent biochips and sensors.

BioMEMS and nanotechnology find many applications within the chemi$\mathrm{cal}$, health-care, biotechnological and manufacturing industries. For instance, drugs with nano-sized particles are highly efficient and more directed in the healing process with miniscule side effects (Lonenberg et al. 1998). Moreover, of high importance are the applications of these technologies for the agricultural and food engineering areas, e.g., exploring biological life processes such as bacterial cell growth and cell concentration, monitoring plant and livestock health, analyzing and determining food quality, and developing novel agricultural products by means of genetic engineering techniques.

\section{The Need for Rapid Diagnostics in Food Safety}

In the instance of food safety, changes in world trade, consumer demand for variety of choices and an increasing, complex regulatory system has created many challenges to effectively monitor the food supply and production. While these concerns from an industry standpoint highlight greater degree of control in the food producing environments (e.g., equipment, 


\section{Percentage-wise distribution of research efforts in different areas}

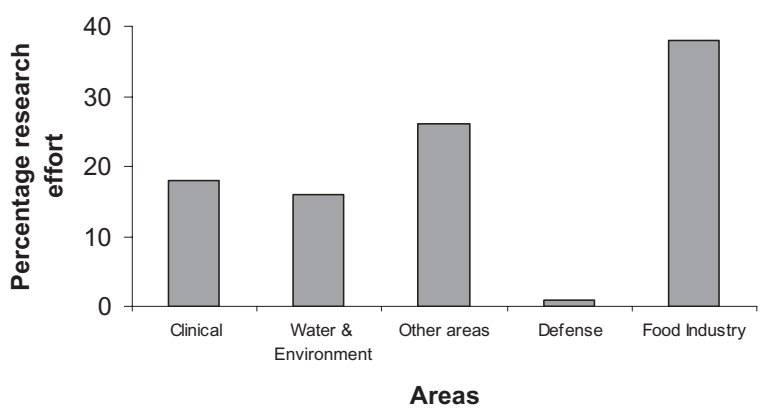

FIG. 1. DISTRIBUTION, BY INDUSTRY OF APPLICATION OF THE PERCENTAGE RESEARCH EFFORT (BASED ON THE RELATIVE NUMBER OF PUBLICATIONS IN CONTEMPORARY LITERATURE)

Reprinted with kind permission from Lazcka et al. (2005).

storage, drainage and disposal facilities) for an overall elimination of pathogen load in the final product, still, it remains a hard-core reality that in any "farm-to-table" scenario, multiple sources, suppliers and steps along the process repeatedly pose a threat to the safety of any food product (Lindberg et al. 2005). This in effect opens the food products with "porous borders" for the spread of disease, bio-threats and food fabrication practices which might affect consumer health. Pathogen control and prevention in all such products are vital.

Figure 1 shows that three primary areas of applications account for over two-thirds of the total research effort in terms of the number of publications in the fields of pathogen detection over the last two decades (Lazcka et al. 2005). These include food industry (38\%), water and environment (16\%) and clinical diagnostics (18\%). As shown in this figure, the food industry remains the main party concerned with pathogen detection and it necessitates the simultaneous testing of multiple samples at a high rate to prevent the outbreak of any epidemic (consider for instance, the 2005 Salmonella outbreak in Spain, which caused the sickness of 2,500 people and one death by salmonellosis) or pandemic (e.g., bird flu, mad cow disease and severe acute respiratory syndrome). However, conventional molecular biology protocols (culture, growth, lyze and analyze), although highly reliable to monitor this pathogen load, are time- and labor-intensive, and require well-trained staff and expensive laboratory equipment, particularly for large-scale sample processing (Grayson et al. 2004). BioMEMS and microscale lab-on-a-chip can be successfully used to provide rapid detection of pathogens and contaminants during food produc- 
tion, processing, storage and handling stages although the sample preparation steps are critical to the success of analysis. The major challenge in preparing an appropriate sample comes from the high probability of micron-sized features or channels getting easily clogged by particles of the food matrix. Thus, a major goal of sample preparation for such devices involves the extraction of the pathogen load from any given food matrix using an off-chip protocol. Microbiological samples can be grouped as solid, liquid, surface or air samples (Fung 2002). A variety of devices like sterile blender (osterizer), stomacher, pulsifier, automated pipetting and diluting instruments, air plates, etc., have been commonplace to this end. Other simplistic ideas for collecting the pathogen load of food surfaces like rubbing the surface with moist cotton swabs, use of adhesive tapes or sterile sponges, etc., have been used very often for pathogen extraction. Bioseparation techniques like filtration through membranes have been employed in an effort to concentrate and recover foodpoisoning bacteria such as Listeria monocytogenes, Salmonella and Escherichia coli. Researchers have also developed a cell concentration recovery system that enables control of feed rate through a syringe connected to a 47-mm diameter membrane holder (Chen et al. 2005). This area, although currently an extremely important research topic, is beyond the scope of this article.

\section{BioMEMS}

In a broader sense, BioMEMS are devices or systems, constructed using techniques inspired by micro/nanoscale fabrication, that are used for performing identification, immobilization, growth, separation, purification and manipulation of single or multiple cells, biomolecules, toxins and other chemical/biological species (Bashir 2004; Kua et al. 2005). For instance, they can be used to monitor the shelf life of an agricultural product, to realize smart drug delivery systems in plants and animals, to detect traces of biological contaminants between samples and to monitor real-time air and water characteristics to reduce pollution (Karunakaran and Jayas 2005), etc. BioMEMS also create new opportunities for the spatial and temporal control of cell growth and stimuli by combining surfaces that mimic complex biochemistries and geometries of the extracellular matrix with micro-fluidic channels (Ali et al. 2006). An example includes growth of bacterial cultures and colonies in micron-sized features with utmost rapidity and high density (Groisman 2005).

A wide variety of applications of BioMEMS for biology and medicine has been presented (Kovacs 1998; Polla et al. 2000; Madou 2002; Bashir and Werely 2006). Currently, there is a high level of focus on bio-particle (10 nm to $100 \mu \mathrm{m})$ manipulation methods to separate and identify cells, proteins, 
viruses and DNA. Most of the methods are based on electrostatics such as electrophoresis, electroosmosis, electrofusion, electrowetting and dielectrophoresis (DEP) (Kua et al. 2005) owing to their effectiveness at microscopic length scales. DEP is a prominent one, particularly for manipulation and separation of large particles like cells (Pohl 1978). Pohl and Hawk (1951) demonstrated the separation of viable and nonviable yeast cells using this technique in the last decade. They extended to other biological cells, including canine thrombocytes, red blood cells, chloroplasts, mitochondria and bacteria (Pohl 1978).

A technique called impedance microbiology has been used for monitoring the cell growth and viability by measuring alternating current impedance between a pair of metallic electrodes immersed in a culture medium with microbial cells. The impedance changes because of the ionic secretions of viable cells with time. Impedance microbiology has been successfully used on BioMEMS devices to detect the presence of bacterial cultures within micronsize chambers and confinements (Gómez et al. 2005). A combination of DEP with impedance microbiology on the same chip was also realized to detect the presence of live bacterial cells with high throughput in food and other samples (Yang et al. 2006).

Micro- and nanoscale mechanical sensors have been shown to have high sensitivity to bio-particles. The change in the resonant frequency of a siliconbased cantilever because of mass change after antigen binding has been measured for detection of viruses and other submicron-sized particles (Thundat et al. 1997). This technique has also demonstrated a capability to detect a single bacterial cell (Illic et al. 2001). Such mechanical systems can also be used for environmental monitoring purposes with high sensitivity and accuracy. We will discuss this further in section 3.

\section{Nanotechnology}

Nanotechnology can be defined as the science of building atomic, molecular or macromolecular-sized materials, devices, structures or systems. It can be used for agricultural or food engineering areas by the following three domains: (1) molecular and cell biology; (2) nanobiotechnology; and (3) nanobioprocessing. Nanotechnology can facilitate a better understanding and characterization of biological mechanisms at the cellular level (Karunakaran and Jayas 2005). It can help to explore the nature, behavior and interactions of biological cells and molecules, facilitating a deeper understanding of plant reproductive sciences, disease diagnostics/prevention and agriculture waste treatments/utilization. In fact, some of the widely used techniques, such as DNA/protein microarrays, polymerase chain reaction (PCR), enzyme-linked immunosorbent assay (ELISA), fluorescence resonance energy transfer 


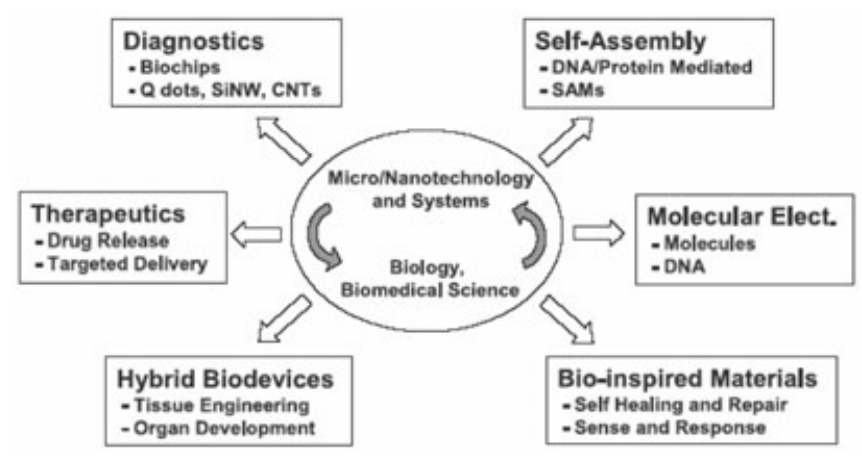

FIG. 2. SCHEMATIC OF THE INTEGRATION OF LIFE SCIENCES WITH BIO-MICROELECTROMECHANICAL SYSTEMS AND MICRO/NANOTECHNOLOGY Reprinted with kind permission from Bashir (2004).

(FRET)-based analysis (arising for conformational changes of single antibody molecules owing to antigen binding), etc. (Shi et al. 2006), have or can benefit from nanotechnology.

Nano-biomaterials can be developed utilizing various natural or synthetic molecules (e.g., DNA) as the basic building units. In the case of DNA molecules, these can be modified to develop novel biomaterials such as nanowires and nanomembranes for nanofiltration processes (Hoek and Jawor 2002). Nanotechnology also offers devices and mechanisms by which bioprocessing can be monitored and controlled. The functional behavior of microbial organisms under different environmental conditions can be determined using cellular and molecular studies. Microbes can be used to effectively remove contaminants from soil, water, etc. (Lei et al. 2006). Another application area is to study the behavior of nanopores within biological or artificial membranes. These pores act as gating devices and can be used for single molecule sensing, nucleic acid sequencing and rapid characterization of bio-analytes. MEMSbased nanopore channels fabricated of silicon have been used as a single DNA molecule sensor. The passage and translocation of single molecules can be measured by monitoring the change in ionic current, enabling the analysis of single cells and detection of very few molecules directly from cell lysates (Chang et al. 2004).

Figure 2 shows a schematic of the integration of life sciences with BioMEMS and micro/nanotechnology. This article is intended to highlight the accomplishments of BioMEMS and nanotechnology for pathogen detection/analysis. Most of the information used has been derived from technical literature with an emphasis to the contributions made by our group to this area. 


\section{METHODS AND MATERIALS FOR MICROFABRICATION OF BIOMEMS}

Some of the widely used materials in microfabrication processes for realizing MEMS devices are silicon, glass and polymers such as polymethyl methacrylate (PMMA), polydimethyl siloxane (PDMS), etc. (Nguyen and Wereley 2002).

\section{Silicon/Glass and Methods of Fabrication}

Silicon is undoubtedly the most popular material in MEMS fabrication. Silicon micromachining technologies are well established and start with high purity single crystalline silicon wafers. Figure 3 shows a schematic of surface and bulk micromachining using different etching and deposition techniques (Madou 2002). A number of layers such as polysilicon, silicon dioxide, silicon nitride, metal and several organic layers can be made by chemical and physical deposition. Also, various wet/dry etching techniques such as reactive ion etching (RIE) can be used to make microchannel and micro-device cantilevers.

Glass mostly consists of silicon oxide (68\% in soda lime, $81 \%$ in borosilicate and $100 \%$ in fused silica) (Braithewaite and Smith 1996) with a few
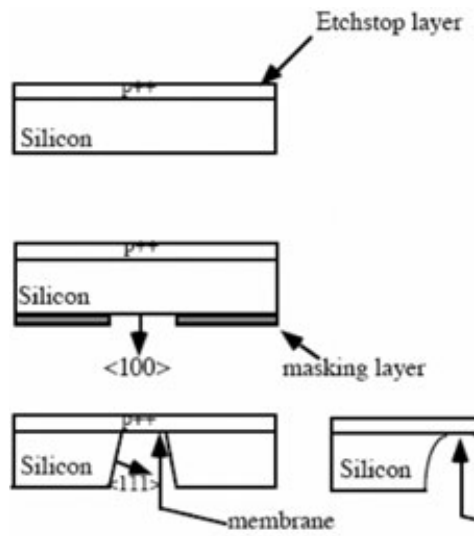

Anisitropic etch

a
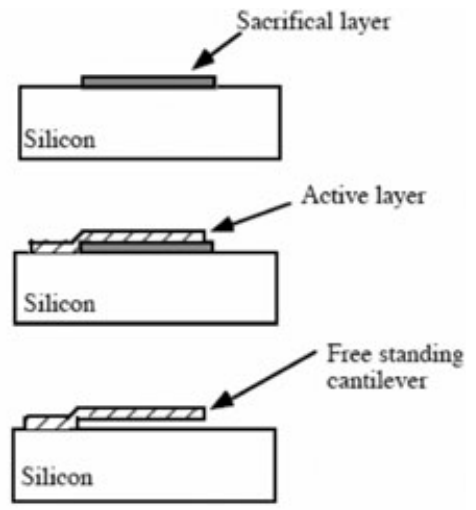

b

FIG. 3. (A) SCHEMATIC ILLUSTRATION OF THE KEY STEPS IN A BULK MICROMACHINING PROCESS. (B) SCHEMATIC ILLUSTRATION OF THE KEY STEPS IN A SURFACE MICROMACHINING PROCESS

Reprinted with kind permission from Trimmer (1997). 
other metal oxides. It has favorable properties such as high mechanical strength, high electrical insulation, high chemical resistance and wide optical transmission range. Glass has been widely used in electrophoresis, electrochromatography for DNA/protein separation, etc. (Ciminska 2006). A majority of glass can be etched using buffered hydrofluoric acid (BHF) with photoresist and metal masking layers. Commercially available glasses like Foturun or FS21 can be photo patterned directly using certain dopant photosensitive materials (oxides of Ag, Sn, Sb, etc.) (Salim et al. 1997). The glasses are irradiated with UV to form crystalline phase and etched selectively using BHF (Ferrari 2006). Deep RIE can also be used to obtain straight walled glass channels (Salim et al. 1997).

\section{Polymers and Methods of Fabrication}

The silicon and glass-based BioMEMS could have drawbacks of higher cost, long processing time and possibly biocompatibility issues (Salim et al. 1997) for which polymers draw attention as an alternative material for BioMEMS. By definition, a polymer is a long, repeating chain of atoms, formed through the linkage of many molecules called monomers. Polymers have some unique properties such as easy fabrication, optical transparency, chemical and biological compatibility, high electrical insulation, good thermal properties and a set of dynamic surface characteristics which make them ideal for realizing BioMEMS architecture. Three most commonly used polymers are PMMA, PDMS and SU-8.

PMMA. PMMA is commercially available as extrusion sheets and is also known as Acrylic, Plexiglass, Perspex, Lucite, etc. It was originally used as a resist material for LIGA techniques (Ferrari 2006). It is thermoplastic in nature, i.e., it softens on heating above its glass transition temperature because of its linearly linked molecular structure. It can be reheated and reshaped into many forms with a multiple number of times which gives it an advantage of reusability. It is noncrystalline in nature and possesses $92 \%$ optical transparency (Henry et al. 2000). Generally, the amorphous polymers possess high transparency and those translucent are normally crystalline. PMMA also possesses other desirable features such as a low frictional coefficient, high chemical resistance and good electrical insulation. It has a dynamic surface which can be modified by X-ray irradiation, oxygen plasma exposure, etc., and its surface properties can be altered to fit any biomedical micro-device application. Methyl monoacrylate monolayer, commonly known as glass glue, can be used as an adhesive for the bonding process (Ferrari 2006).

SU-8. The need for making thick photoresists for high aspect ratio structures in a simpler and inexpensive way is very well met by SU-8. This resist is 
supplied as a liquid comprised of an epoxy resin, a solvent (normally cyclopentanone) and a photoacid generator that generates the acid on exposure to light. The portions of the negative photoresist exposed to the UV light are left insoluble to liquid developer. SU-8 can be patterned with high aspect ratios, resulting in nearly vertical sidewalls for thick films. It also exhibits good chemical and temperature resistance.

PDMS. PDMS is a polymer that has an inorganic siloxane backbone with methyl groups attached to silicon. It is made by mixing a pre-polymer with a curing agent, both commercially available. PDMS has a low interfacial energy, which makes it uniquely hydrophobic (Hillborg and Gedde 1998). However, this interfacial energy can be modified using oxygen plasma which makes its surface highly dynamic (Bhattacharya et al. 2006). This property of PDMS makes it a good material for building enclosed micro-fluidic chambers and channels and also for other BioMEMS applications. PDMS is stable against humidity and temperature. It is optically transparent and can be cured by heat or UV light. It has a high self-sealing ability to a variety of surfaces and is very durable. These properties make PDMS an ideal material for soft lithography (Duffy et al. 1998). PDMS also presents a number of drawbacks such as volume change and elastic deformation. PDMS is also biocompatible, and hence mammalian cells can be cultured directly on this material and PDMS devices can be implanted in a biological environment.

PDMS is replica molded using an SU-8 mold on glass or silicon with standardized photolithography and developing techniques as detailed earlier. A negative of the desired device is obtained with the photoresist defining the desired features and the negative is used to cast a device using PDMS. PDMS is then heat cured into a rubbery solid and retrieved from the SU-8 mold by peeling off.

\section{BIOMEMS FOR PATHOGEN DIAGNOSTICS AND DETECTION}

Pathogen detection is one of the most widely explored areas in BioMEMS research. Culture and colony counting methods and PCR have been the two conventional and most selective/reliable methods in all molecular biology laboratories although they take hours to days to provide conformity. The emphasis of detection technologies has been moved to BioMEMS/sensor technology because this provides equally reliable results in a fraction of time of the conventional methods. In general, the use of micro/nanoscale detection technologies has the following potential advantages:

(1) They can provide higher sensitivity by reducing the sensor size to the scale of the analyte to be detected. 
(2) They can reduce the effective reagent volumes and are cost effective.

(3) They can significantly reduce the detection time owing to the high concentration levels of analytes in microscopic volumes at an enhanced speed.

(4) They have higher portability due to their miniaturized nature.

We will present the remaining review in the following parts. First, BioMEMS detection modalities are presented, followed by some examples of biochips and biosensors. We will next cover the micro-fluidic biochip platform which utilizes cell capture techniques such as DEP and antibody immobilization, growth and viability studies using impedance microbiology, $\mathrm{pH}$ detection and cell lysis/PCR for complete detection. We will also briefly review nanotechnology-inspired detection strategies such as hybridization microarrays and nanopore-based detection.

\section{Detection Protocols for BioMEMS and Biosensors}

Biosensors are devices which combine a biologically sensitive element with a physical or chemical transducer to selectively and quantitatively detect the presence of specific compounds in a given external environment. In the past few years, the dual demands for increased range of analytes and decreased size are driving biosensors towards micro- or even nano-arrays. The revolutions in BioMEMS technology has led to fundamental breakthroughs in the way materials, devices and systems are designed, manufactured and utilized, which has made BioMEMS an inseparable part of biosensor technology. The integration of biosensor and BioMEMS has resulted in a number of microbiochips that can be used to detect DNA/protein, cells or other small biomolecules with high accuracy and great rapidity. There are many detection methods used in BioMEMS sensors out of which mechanical, electrical and optical means are the most widely used ones for signal transduction. Figure 4 shows a schematic containing a summary of these key detection modalities in biochips and BioMEMS sensors.

BioMEMS and Mechanical Transduction. The advancement in MEMS technology during the last two decades has facilitated the development of sensors that rely on transduction of mechanical energy (Moulin et al. 2000). Microfabricated cantilevers are one of the most widely used microstructures as mechanical sensors and they were first utilized in atomic force microscopy (AFM) (Binnig et al. 1986). A cantilever is a diving board-shaped, single clamped, suspended beam. Figure 5a illustrates a comparison between commercially available cantilever tips (as used in AFM) and a human hair. Microfabricated cantilevers with readout means that are capable of measuring $10^{-12}$ $10^{-6} \mathrm{~m}$ displacements can operate as detectors of surface stresses (Butt 1996), 


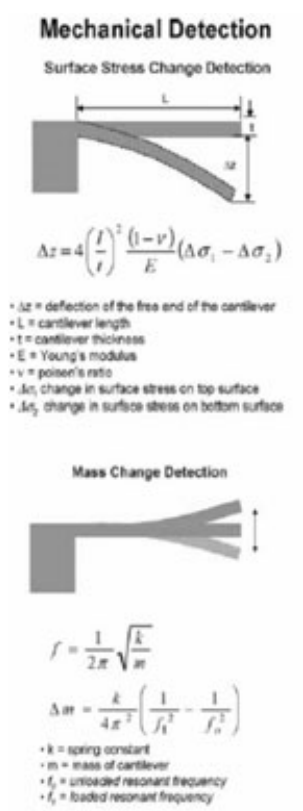

a

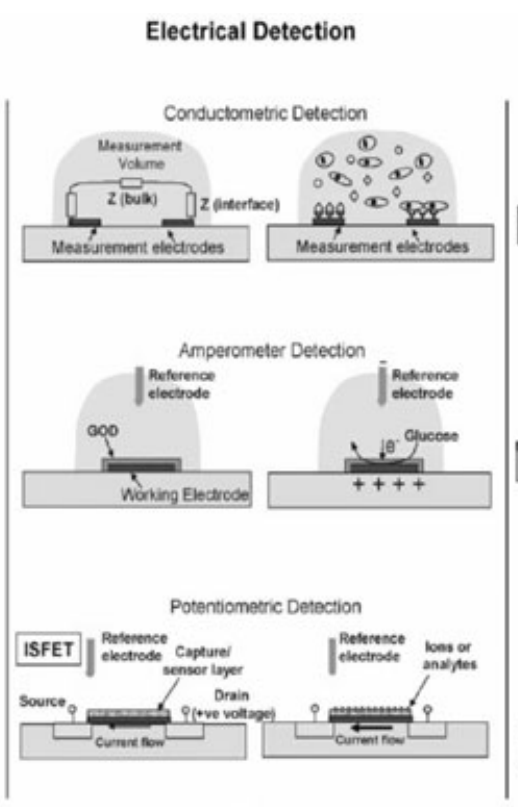

b
Optical Detection

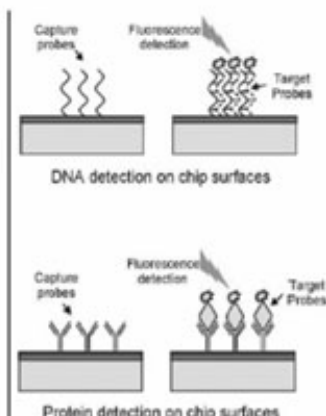

Protein detection on chip sulaces

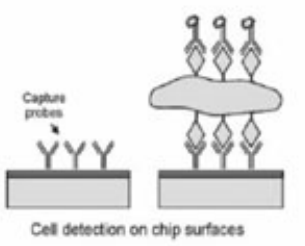

C

FIG. 4. DIFFERENT MODALITIES OF DETECTION FOR BIOSENSOR Reprinted with kind permission from Bashir (2004).

extremely small mechanical forces (Berger et al. 1996), charges (Cleland and Roukes 1998), heat flux (Barnes et al. 2002), etc. Biochemical entities can also be mechanically detected using micro/nanoscale cantilever sensors.

The basic working principle of cantilever sensors is that any physical, chemical or biological stimuli can affect the mechanical characteristics of the micromechanical transducers in such a way that a resulting change can be measured using electronic (by using piezoelectric or piezoresistive materials on the surface of the cantilevers), optical (laser reflecting from the cantilever surface into a quadrature position detector, as in an AFM) or other means (Sarid 1991).

There are two main sensing methods for a microcantilever system: (1) stress detection mode and (2) mass detection mode (Fig. 4). In the stress sensing mode, a biochemical reaction is performed selectively on one side of the cantilever, thus changing the surface-free energy and surface stress on both sides. This results in a measurable bending of the cantilever and a label-free detection of the bio-analyte can be easily performed. The stress sensitivity is increased by reducing the spring constant of the cantilever (Lavrik et al. 2004). 


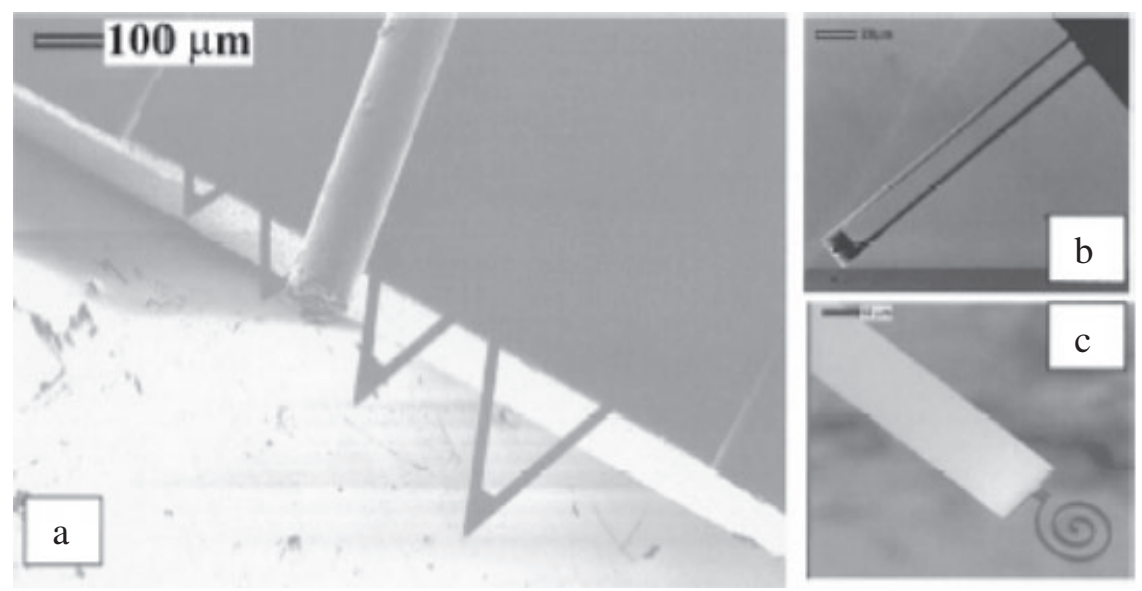

FIG. 5. MICROELECTROMECHANICAL SYSTEMS-BASED CANTILEVER DEVICES

(A) Commercially available cantilevers used in atomic force microscopy as compared to a human hair. (B) and (C) Modified rectangular cantilevers with increased thermal isolation are optimized for calorimetric detection.

Reprinted with kind permission from Lavrik et al. (2004).

In the mass detection mode, the cantilever vibrates at its resonant frequency by an external disturbance or ambient thermal noises. The resonant frequency shift is measured to find added masses, or analytes or biomolecules bound on the cantilevers using any of the means described earlier, provided that the spring constant remains unaltered. To increase the mass sensitivity of the cantilever, its own mass should be made smaller, the quality factor should be enhanced and the detection system should be sensitive to detect small frequency shifts. As the device size approaches the nanoscale, their mechanical behavior starts resembling the vibrational modes of molecules and atoms (Lavrik et al. 2004). Nano-mechanical resonators with a mass of $2.34 \mathrm{E}-18 \mathrm{~g}$ and a resonance frequency of $115 \mathrm{MHz}$ have been fabricated and displacements as small as $2 \mathrm{E}-15 \mathrm{~m} \mathrm{~Hz}^{-1 / 2}$ have been measured (Knobel and Cleland 2003). Mass sensitivity of only a few femtograms has been recently reported using nanoscale resonators (Lavrik and Datskos 2003).

A large number of cantilever-based biosensors have been reported. Subramanium et al. (2002) detected the presence of glucose in an aqueous medium by utilizing the ultrahigh calorimetric sensitivity of a biomaterial microcantilever system. Glucose oxidase enzyme immobilized on the surface of a 320- $\mu \mathrm{m}$ long, gold-coated silicon nitride cantilever generated heat in the presence of glucose. Baselt et al. (1996) demonstrated the first force amplified biological sensors by studying cantilever behaviors in a magnetic field. They would detect molecules labeled with magnetic beads. Raiteri et al. (1999) 
explored the high sensitivity of cantilever transducers to interfacial stress changes in their work on a biosensor for a herbicide. They detected bending responses of microfabricated cantilevers optically, corresponding to interaction between surface immobilized herbicide and anti-herbicide antibody in an aqueous solution. The cantilever deflections were monitored in this case in a continuous flow system at a flow rate of $0.5 \mathrm{~mL} / \mathrm{min}$. Fritz et al. (2000) have demonstrated direct label-free detection of DNA and protein molecule using silicon cantilevers. They have performed a sensitive and specific monitoring of oligonucleotide hybridization using arrays of functionalized cantilevers and optical readouts. Thundat et al. (1997) were able to show detection capabilities up to a single base pair mismatch using a cantilever transducer placed in flow cells. Moulin et al. (2000) used microfabricated cantilevers to measure surface stress changes associated with nonspecific adsorption of immunoglobin $\mathrm{G}$ and bovine serum albumin (BSA) on gold surfaces. Microcantilevers based on surface stress measurements are very sensitive to subtle differences in preparation and purification of proteins that are otherwise identical and cannot be differentiated using other characterization methods (Moulin et al. 2000). They also proposed clinically relevant cantilever-based biosensors for low density lipoproteins (LDL) and their oxidized form (oxLDL). The cantilevers in this case were heparinized followed by BSA treatment for saturation of nonspecific binding sites. The cantilevers showed pronounced bending in opposite directions upon exposure to LDL and oxLDL, respectively. The adsorption triggered stress changes were considerably slower in this case than the binding kinetics rate as determined separately using a surface plasmon resonance sensor. This suggests a possibility of the cantilever set to be capable of detecting postabsorption changes in molecular configuration. Cantilevers coated with environmentally sensitive hydrogels such as $\mathrm{pH}$-sensitive PMMA can also be used to induce a stress on the cantilever surface by volume expansion (Bashir et al. 2002). The detection of larger entities such as cells or antibody has not been reported using stress mode. This might be attributed to the fact that the stress mode is based on the basic premise that the whole cantilever surface will change its energy configuration, which may not be the case for the capture of larger entities.

Illic et al. (2001) have demonstrated an ultrasensitive detection approach of biological species in air using smaller cantilevers in the resonance mode. The silicon nitride cantilevers were around $5 \mu \mathrm{m}$ long and had resonance frequencies in the megahertz range. Mass sensitivity of the designed cantilever sensor was sufficient to detect the mass changes corresponding to the attachment of a single E. coli cell on its surface (Fig. 6a) (Illic et al. 2001). Additional studies have demonstrated the use of cantilevers to detect and monitor the growth of E. coli cells and fungal spores (Aspergillus niger) (Gfeller et al. 2005; Nugaeva et al. 2005). For real-time biological detection in liquid, a 


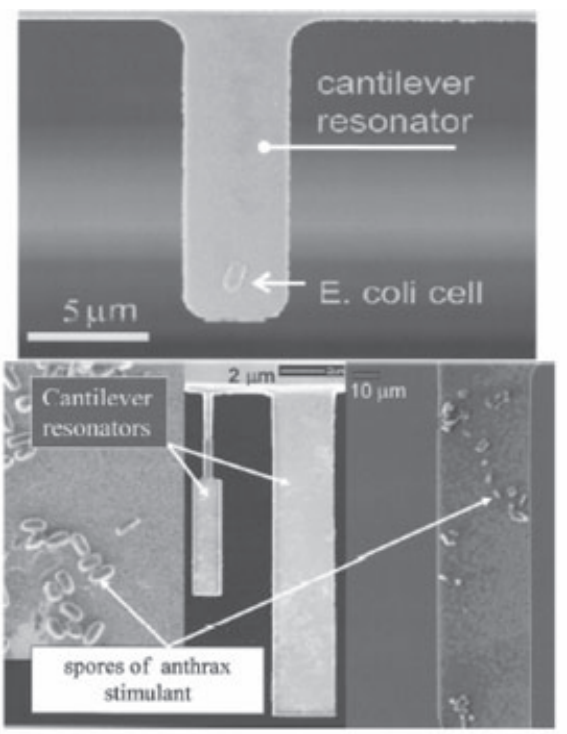

a

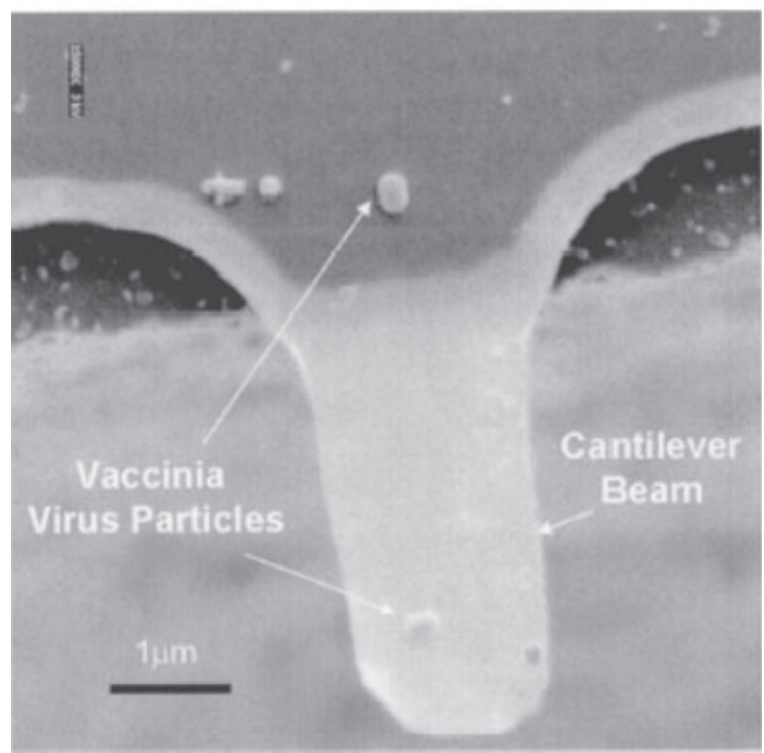

b

FIG. 6. (A) RESONATING CANTILEVER DEVICES THAT PROVIDE MASS SENSITIVITY SUFFICIENT FOR A SINGLE CELL DETECTION OF ESCHERICHIA COLI. (B) SCANNING ELECTRON MICROGRAPH SHOWING A CANTILEVER BEAM WITH A SINGLE VACCINIA VIRUS PARTICLE

Fig. 6a reprinted with kind permission from Illic et al. (2001) and Lavrik and Datskos (2003). Figure $6 \mathrm{~b}$ reprinted with kind permission from Gupta et al. (2004b). 
novel hollow microcantilever was reported in which the liquid flows inside the cantilever, allowing measurement of the changes in resonant frequency to be done in air (Burg and Manalis 2003). This hollow cantilever maintains high quality factors by operating in air, but can still perform real-time measurements in liquid by introducing the liquid inside the cantilever.

Our group has applied resonant cantilever biosensors for detection of bacterial cells and viruses (Gupta et al. 2004a,b). The fabricated silicon cantilevers were 4-5 $\mu \mathrm{m}$ long, $1-2 \mu \mathrm{m}$ wide and $20-30 \mathrm{~nm}$ thick for vaccinia viruses (Fig. 6b) and 78-79 $\mu \mathrm{m}$ long, 23-24 $\mu \mathrm{m}$ wide and 300-500 nm thick for Listeria cells. We have demonstrated the detection of a single vaccinia virus and Listeria cell with an average mass of $9.5 \mathrm{fg}$ and $85 \mathrm{fg}$, respectively. Gupta et al. (2006) also showed theoretically and experimentally that the resonant frequencies of the nanoscale cantilever sensor may actually decrease or increase after attachment of protein molecules, which arises from a sizespecific modification of diffusion and attachment kinetics of biomolecules on the cantilevers. We have also recently performed detection of 50-100 spores in water using a planar rectangular geometry cantilever (Davila et al. 2006).

BioMEMS and Electrical Detection. Electrical or electrochemical detection strategies are commonplace in many biosensors. These techniques are more amenable to miniaturization concepts compared to bulky optical detection setup. Electrochemical sensors are classified into amperometric (measuring the current variation at an electrode as a result of a redox process), potentiometric (measuring the change in electric potential at the electrodes as a result of ions formed by a redox process) and conductometric (measuring conductance changes associated with variation in the medium ionicity) (Keller 1998).

Amperometric sensors have been widely developed for the determination of the biochemical oxygen demand (BOD) for the measurement of biodegradable organic polymers in aqueous media (Liu and Mattiasson 2002). The conventional method for measuring BOD is based on monitoring microbial respiration taking 5-6 days. This has been currently replaced by the amperometric oxygen electrode transducer mounted with one or more microorganisms which metabolize organic pollutants to produce oxygen. The various strains used single-handedly or combinatorially include Torulopsis candida (Sangeetha et al. 1996), Trichosporon cutaneum (Yang et al. 1997), Pseudoman putida (Marty et al. 1997), etc. Amperometric biosensors using microbes for detection of ethanol is another center of focus because of its importance in fermentation industry and clinical toxicology (Chee et al. 1999). Different microorganisms like Trichosporon brassicae (D'Souza 2001) and Acetobacter aceti (Karube et al. 1992) have been widely immobilized on oxygen electrodes to form ethanol biosensors. Sugar is an impor- 
tant ingredient of different media and can be sensed using amperometric biosensors by the use of Saccharomyces cerevisae and E. coli mutants (Tkac et al. 2000). The most prevalent example of amperometric sensors is a glucose detection sensor based on glucose oxidase, an enzyme which generates hydrogen peroxide and gluconic acid in the presence of oxygen, glucose and water (Poyard et al. 1998). Hydrogel and conducting electroactive polymer have been integrated to develop electroactive hydrogels to trap enzymes for biosensor platforms (Yamana et al. 2001). Detection of DNA hybridization is carried out by site-specific attachment of a ferrocenyl derivative into a DNA oligonucleotide which acts as an electrochemical probe (Fodor et al. 1991). A full complementary metal oxide semiconductor (CMOS) chip with specialized backend processes has been developed for detection of DNA using electrochemical methods.

Conventional potentiometric sensors consist of an ion-selective electrode or a gas-sensing electrode as the working electrode which is monitored with respect to another reference electrode. In some cases the working electrode is immobilized with a layer of microbes that consumes the electrolyte and generates a change in potential resulting from ion accumulation or depletion. Ammonium ion-selective electrode was coupled with urease yielding Bacillus sp. isolated from the soil to develop a disposable potentiometric sensor for monitoring the presence of urea in milk (Heller et al. 2000). A sucrose biosensor was formulated based on the same mechanism with another organism, Saccharromyces cerevisae (Hintsche et al. 1995). Other common potentiometric sensors integrable with microelectronics are the ion-sensitive field effective transistors (ISFET) and the chemical field effective transistors (chemFET). Sensors with ion-selective ionophores in modified poly (vinyl chloride) have been used to detect analytes from human serum (Cui et al. 2001). Cellular respiration and acidification due to the activity of cells have been measured using Complementary Metal Oxide Semiconductor technology. A new type of silicon-based light addressable potentiometric sensor for monitoring hydrogen ion was realized using E. coli WP2 to fabricate a potentiometric assay for tryptophan (Seki et al. 2003). Potentiometric sensors have been downscaled to nanometer dimensions through the use of silicon nanowires and carbon nanotubes as FETs (Besteman et al. 2003). These sensors have a very high surface area to volume ratio enabling more surface coverage and higher sensitivity. Although the integration of these technologies in a lab-on-a-chip is very challenging, recently our group has used some top-down fabrication techniques to demonstrate such nanoscale structures (Elibol et al. 2003).

Many cellular and microbial activities involve a change in ionic species, implying an associated change in the conductivity of the reaction solution. The conductance measurements are extremely sensitive and can be used to derive information about the cause although solution conductance may be substan- 


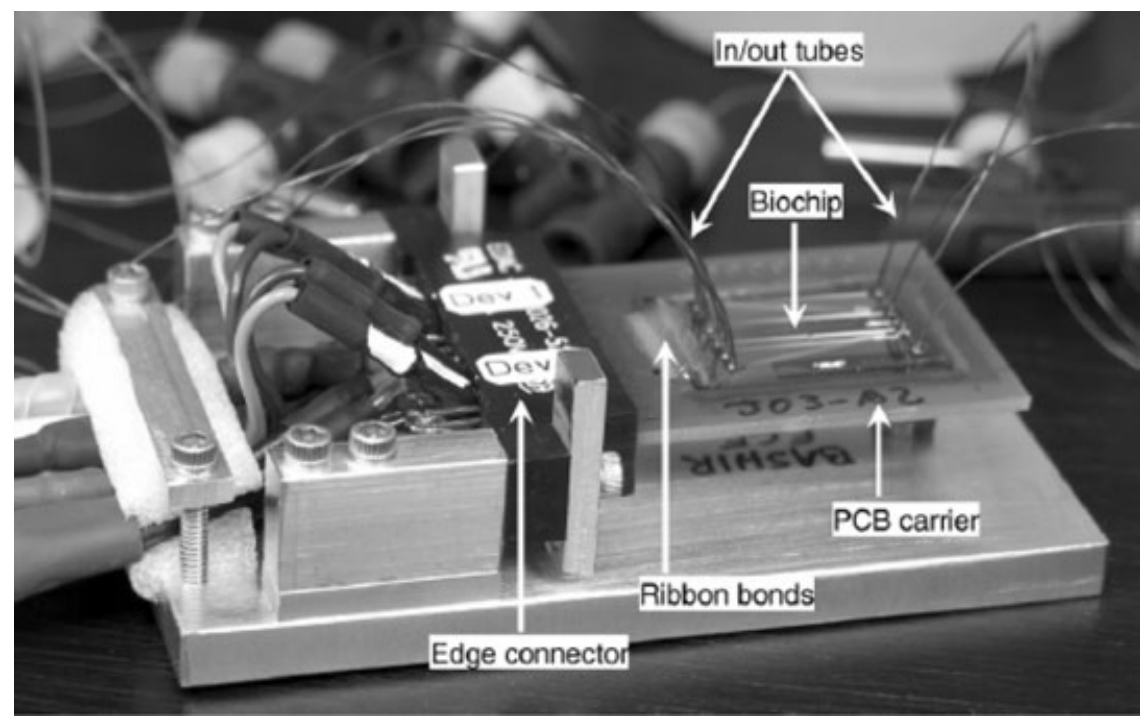

FIG. 7. PACKAGED VIEW OF THE BIOCHIP CONNECTED TO THE MEASUREMENT AND CONTROL SYSTEM

Reprinted with kind permission from Gómez et al. (2005).

tially nonspecific in nature (Tran 1993). A single use conductivity and microbial sensor has been demonstrated by Bhatia et al. (2003) to investigate the effect of concentration of metabolites of E. coli (a finding which could be relevant to the recent finding of $E$. coli in spinach fields in the U.S.A.). Gómez et al. (2005) have demonstrated the measurement of impedance due to metabolic activities of bacterial cells as they grow within micro-fluidic biochips. Figure 7 shows a picture of the biochip which senses an impedance trend with growth of the bacterial cells. These hybrid systems combine the physicochemical and biological sensing on a miniaturized scale which could greatly increase the ease of comparative data accumulation.

BioMEMS and Optical Detection. Optical biosensors work on the basis of changes in optical properties such as UV-Vis absorption, bio- and chemiluminescence, reflectance and fluorescence brought by the interaction of the biocatalyst with the target analyte. Optical biosensors offer several advantages such as sensitivity, flexibility, resistance to electrical noise, etc. Bioluminescence is the emission of light by certain living microorganisms and it can be used to monitor the progress of bioprocesses with time.

The bacterial lux gene has been widely applied as a reporter either in an inducible manner, where the reporter is fused to a promoter which is regulated 
by the concentration of the compound of interest, or in a constitutive manner, where the promoter is expressed as long as the organism is alive and active, and fuses with the reporter molecule (Belkin 2003). In order to monitor the nutrients in an aquatic ecosystem, a bioluminescent sensor comprised of Cyanobacteria has been reported (Schreiter et al. 2001). The reporter strain Synechococcus (in the bacteria) harbors a reporter protein luciferase under the control of an inducible alkaline phosphatase promoter, which can only be induced under phosphorous limitations that can be used to monitor the total phosphorous content in water. The environmental problems caused by industrial and agricultural pollution make the demand for toxicity detection methods ever increasing. The online pollutant and toxicity testing using bioluminescence biosensors outshines in terms of sensitivity and reliability. The luxmarked rhizobacterium Pseudomonas fluorescens has been developed to evaluate the pollution stresses due to higher presence of carbonaceous materials (Porteous et al. 2000). The lux-marked whole cell biosensors are used interactively for phenol monitoring in water samples.

Fluorescence spectroscopy has been widely used and applied to detection of bio-analytes principally because of its enhanced sensitivity. ELISA based on antibody-antigen interaction used to detect cells within microchips shows the direct integration of molecular techniques inspired by nanotechnology (as described later) with BioMEMS. A majority of detection schemes in microarrays and numerous lab-on-a-chip assays utilize fluorescence spectroscopic techniques (Bashir 2004). Detection of nucleic acids on chips using a real-time quantitative PCR protocol is a direct application of fluorescent detection techniques in BioMEMS (Ibrahim et al. 1998). Hydrogel-based photodefinable micro-chambers have been used by Ibrahim et al. (1998). to obtain DNA hybridization assays on micro-beads. All detection in this case has been carried out fluorescently (Ibrahim et al. 1998).

\section{Lab-on-a-Chip}

Lab-on-a-chip is a system or devices that can be used to perform a combination of analyses on a single miniaturized device for biological and clinical assays. Some of the key application areas of this technology belong to the areas of life science research (genomics, pharmacogenomics and proteomics), drug delivery and point-of-care diagnostics. Many of these devices include multiple analysis steps, e.g., sample preparation (including cell concentration and sorting), growth and detection, cell lysing and PCR, cell growth and detection by impedance microbiology techniques (as detailed earlier), and also other detection strategies to give conformity at every stage in the chip (Fig. 8). This increases detection accuracy and reduces the chances of false positives. Here we will review the efforts of various research groups to perform 


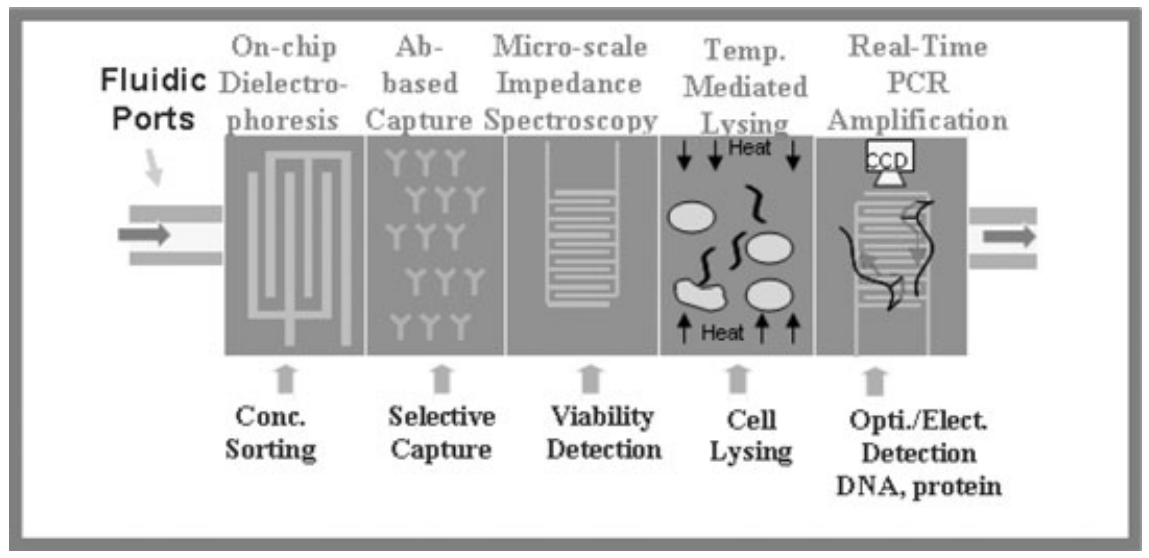

FIG. 8 SCHEMATIC OF AN INTEGRATED PLATFORM FOR A LAB-ON-CHIP COMPLETE DETECTION OF CELLS AND MICROORGANISMS

Borrowed with kind permission from Bashir (2004) and slightly modified.

all above mentioned functions with specific details of contributions made by our group to analyze food pathogens.

Most of the bio-particles are separated using DEP techniques as detailed earlier. The term DEP was first used by Pohl (1978), which he described as the translational motion of neutral matter caused by polarization effects in nonuniform electric fields, in particular, traveling wave DEP and electrorotation (Voldman 2006). In earlier stages, DEP was performed using pin-wire electrodes, restricting DEP techniques for only bigger sized particles (micron size and above). In recent years, with the advent of photolithographic techniques, microelectrodes with dimensions as small as $0.5 \mu \mathrm{m}$ can be fabricated, thus generating very large electric fields sufficient to manipulate submicron-level particles (DNA, protein, viruses, etc.). Yang et al. (1997) applied DEP to collect and selectively capture Listeria cells on the surface of a microchannel from a continuously flowing stream (see Fig. 9). The advantages of DEP concentration and selective antibody capture were demonstrated. Monoclonal anti-Listeria antibody was immobilized onto the surface of the DEP chamber using biotin-streptavidin conjugation. L. monocytogenes V7 cells and E. coli K12 cells were separated using the biochip.

Our group is among the first to fabricate integrated silicon-based biochips for impedance detection of microbial metabolism (Gómez et al. 2003). The chip has a network of microchannels for sample injection and a nanoliter chamber for bacteria cell capture and detection. The chamber contains one set of interdigitated microelectrodes (IME) for DEP capture of bacterial cells from the fluid, and one set of IME for impedance measurement of the metabolic 

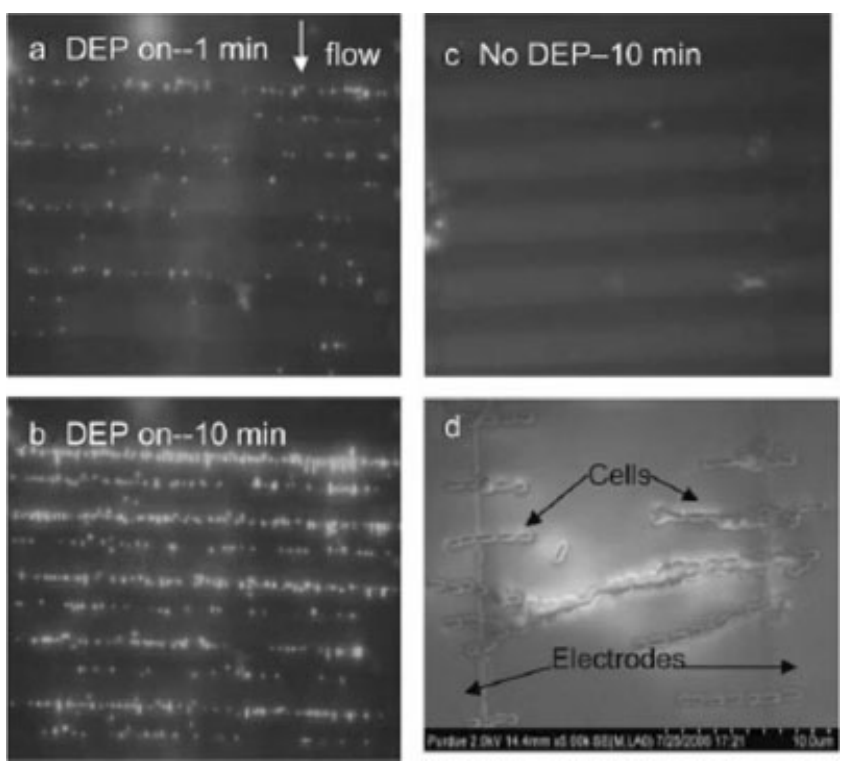

FIG. 9. DIELECTROPHORESIS (DEP)-BASED CELL CAPTURE

(A) $1 \mathrm{~min}$ and (B) $10 \mathrm{~min}$ of the sample flow $(0.2 \mu \mathrm{L} / \mathrm{min})$ into the DEP channel with $20 \mathrm{~V}$ (peak to peak) applied at $1 \mathrm{MHz}$ to the interdigitated electrodes. (C) No cells visible without DEP. (D) Scanning electron micrograph picture of the DEP-collected Listeria cells in the micro-fluidic channel.

Reprinted with kind permission from Yang et al. (2006).

activity during bacterial growth. Taking the advantage of the small volume of the biochip, this new technique of "impedance microbiology-on-a-chip" concentrated bacterial cells from a dilute sample using DEP by factors on the order of $10^{4}-10^{5}$ into a small chamber on the order of a nanoliter. Such concentration eliminates the need to enrich the bacterial population by long culture steps, which drastically reduced the total assay time. We have achieved the detection time of $1 \mathrm{~h}$ in detecting the sample with 50-200 cells using this impedance biochip (Gómez et al. 2005). Further, it has been demonstrated that sterile media did not exhibit any clear metabolic signal. The bacterial sample injected without the DEP concentration generated a metabolic signal indicating exponential growth at approximately $7.5 \mathrm{~h}$.

Other most prominent demonstrations of micro-fluidic devices have been in the areas of flow cytometry and integrated gene analysis systems on chips. Several of these systems have been made commercially available. Various physicochemical characteristics of cells suspended in a medium, such as number of live cells in a given sample (as in cell viability assays), their shapes, sizes, presence of tumor markers on cell surfaces and cell cycle distribution, 

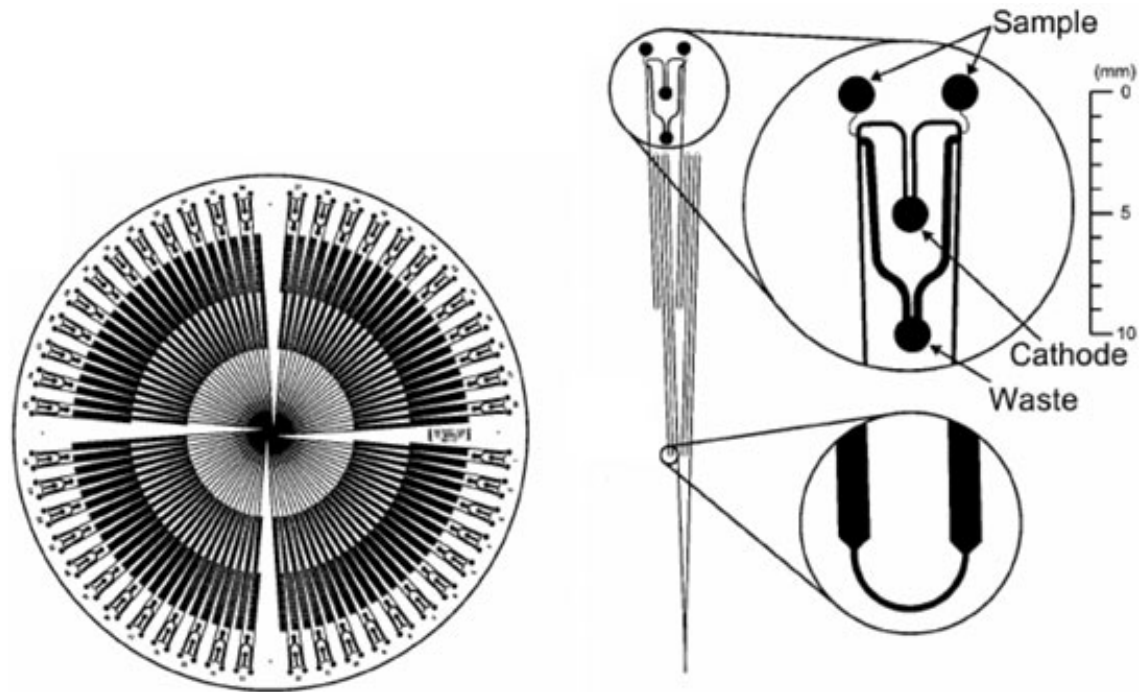

FIG. 10. OVERALL LAYOUT OF THE 96-LANE DNA SEQUENCING MICROCHANNEL PLATE WITH AN EXPANDED VIEW OF ONE LANE

The effective channel length between the sample injector and the waste collector port in every lane is around $15.9 \mathrm{~cm}$.

Reprinted with kind permission from Paegel et al. (2002).

can be measured by flow cytometry. Electrokinetic transport of E. coli cells has been demonstrated using flow cytometric techniques wherein four microchannels intersecting perpendicularly on glass substrates coated with PDMA (to prevent cell adhesion) were used to separate in a fluorescence activated mode. Labeled antibodies to $E$. coli cells were used for optical detection with a throughput of 30-85 cells/sec (Gawad et al. 2001). Viability assaying performed with on-chip staining of the bacterial cells showed that most of the cells survived the applied electric field. Cells can be differentiated through fluorescent, magnetic or dielectrophoretic means ( $\mathrm{Hu}$ et al. 2005).

The integrated gene analysis systems were demonstrated using PCR, electrophoresis and optical detection to realize a micro total analytical system almost a decade ago. DNA detection in nanoliter size samples using a device with integrated fluidic channels, heaters, temperature sensors and fluorescence detectors has been described earlier (Dittrich et al. 2006). A set of 96 microchannels radially on a silicon glass platform has been demonstrated for reading multiple specimens in a very short time (Paegel et al. 2002) (Fig. 10). Another area of rapidly increasing interest is the use of BioMEMS and micro-fluidic architectures for drug delivery applications. Other essential components used 
in a complete lab-on-a-chip include micro pumps, valves, mixers, metering elements, cell lysing elements, laser tweezers, semiconductor optics on chip, etc. (not reviewed here).

\section{Nanotechnology-Inspired Detection}

Hybridized Microarrays. DNA molecules themselves are a perfect set of reagents to identify particular DNA sequences. This is because of the strong sequence-specific base pairing between complementary DNA strands. Here one strand of the DNA is considered the sample and the other is the probe. The analysis of a particular DNA sequence consists of asking whether a probe can find its target in the sample of interest. If the probe does so, a double-stranded DNA complex is formed. The process is called hybridization, and information of the sequence can be extracted on the knowledge of the initial single strand material. The earliest hybridization experiments were carried out in homogenous solutions (Cantor and Smith 1999). The hybridization was allowed to proceed for a fixed period of time and then, a physical separation was performed to capture double-strand materials by using columns filled with hydroxyapatite. The amount of double-strand materials could be identified by using a radioisotopic label on the probe or the target.

Modern hybridization protocols involve the immobilization of the probe or the target on a solid support mostly by chemical means. In the array format single strands of known sequences are placed on specifically known sites. This can be realized by optical or electrical means. The optical approach involves selective deprotection of sites where known sequences of single strands can be built base by base. The electrical approach is based on the negative charge on a DNA molecule which can be electrophoretically transported to the specified locations on chip surfaces (Bashir 2004). The electrical approach can be used to build capture probe immobilization pixel by pixel as shown in Fig. 11. The complementary half strand from the sample or the probe pre-labeled with a radioisotope or a fluorophore is next flown into the same substrate and allowed to hybridize. The nonhybridized material is then washed off and the surface is analyzed by picking up the radio or optical signals. By having a prior knowledge about the sequence on the probe we can get information about the sample. An advantage of this method is the enhanced processing speed of the samples.

Nanopore Sensors. Nanoscale pores within biological membranes are promising architectures for single molecule sensing (Fig. 12). Nucleic acid sensing and protein detection at single molecule levels can potentially be achieved using nanopore channels (Li et al. 2003). Chang et al. (2004) have demonstrated the translocation of $200 \mathrm{bp}$ DNA through a $6 \mathrm{~nm}$ diameter, 50-60 $\mathrm{nm}$ length nanopore channel. In the work, current pulses between two 

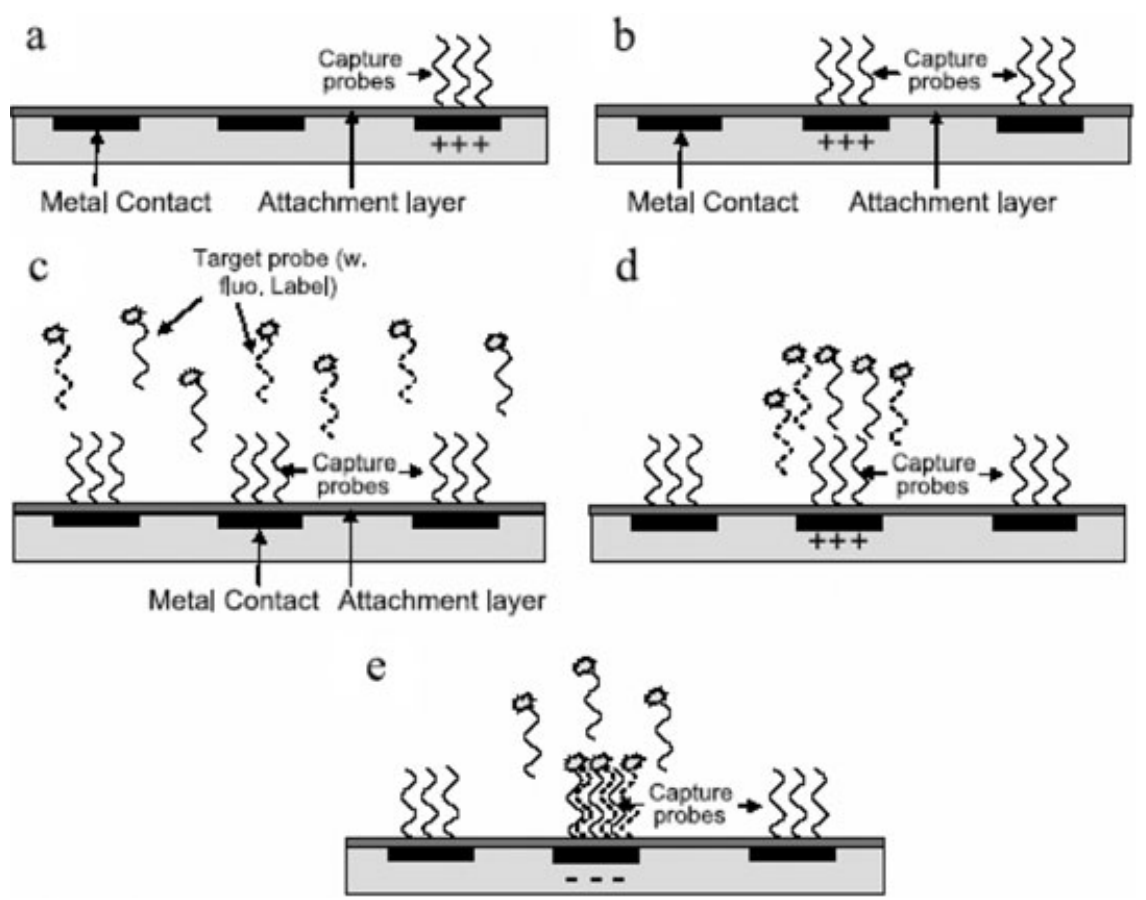

FIG. 11. SCHEMATIC ILLUSTRATING THE ELECTROPHORETICALLY MEDIATED SYNTHESIS OF DNA MICROARRAYS

(A) and (B) Capture probes can be sequentially addressed at specific sites. (C) Target probes and label are added. (D) Voltage applied at specific sites increases the local concentration and hybridization is performed. (E) The unhybridized strands are repelled away.

Reprinted with kind permission from Bashir (2004).

electrodes placed in two conductivity flow cells gated from each other with a silicon nanopore as the only flow path between them. The experimental results of this study demonstrated that the charge on the DNA could be detected in nanopore channels by measuring the current in the Debye Layer of the DNA at the single molecule level. This general direction of research can potentially result in label-free electronic detection of single molecules for identification of target genes of interest or even for direct label-free sequencing of long strands of DNA molecules.

\section{CONCLUSIONS}

MEMS have many characteristics that make them appealing for biological applications, including the ability to control their physical and chemical 


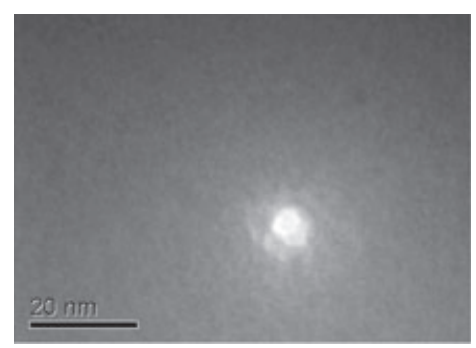

a

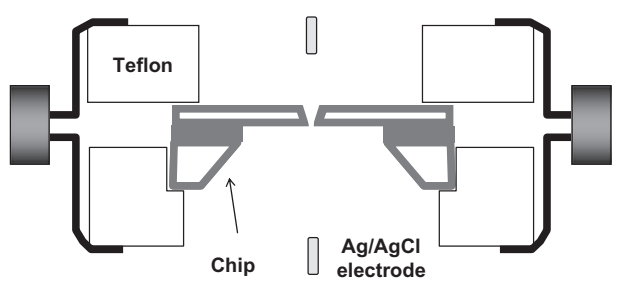

b

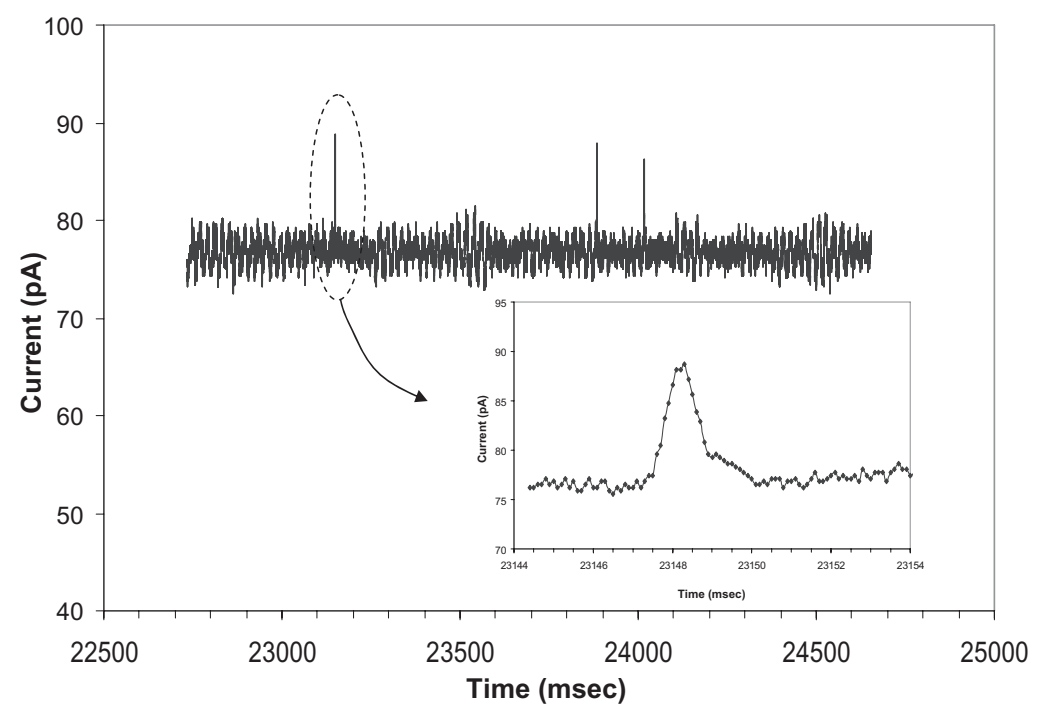

$\mathrm{c}$

FIG. 12. (A) TRANSMISSION ELECTRON MICROSCOPE IMAGE OF THE SMALLEST DIAMETER OF THE NANOPORE CHANNEL IN THE OXIDIZED SILICON MEMBRANE. (B) CROSS-SECTION OF THE OXIDIZED SILICON MEMBRANE. (C) TYPICAL PULSES MEASURED FOR THE TRANSLOCATION OF THE 200 bp dsDNA THROUGH THE NANOPORE CHANNEL

Reprinted with kind permission from Chang et al. (2004).

characteristics on the micro/nanometer scale. A lot of progress (some described earlier) has been made in the areas of BioMEMS and nanotechnology for pathogen detection. A very large number of accomplishments have been reported in the various modes of detection technologies (mechanical, electrical and optical). A current goal of all BioMEMS and nanotechnology research is detection and sample manipulation schemes at a molecular/cellular level. This will lead to a very close monitoring and control of various patho- 
gens that might be translated to individuals through food, environment or any other route. Micro-fluidic based lab-on-a-chip devices have provided important steps towards realizing the single molecule/cell detection. Several schemes of cell trapping, concentration, growth, monitoring and molecular biology-inspired detection schemes have been demonstrated using microfluidic platforms. The technology involved in integrated gene analysis systems and flow cytometers/bio-particle separators is currently very well matured to an extent that they are being commercialized. The integration of BioMEMS and nanotechnology will enable us to probe, measure and explore the nanomachinery in the biological world. Consider for instance the potential of nanopore technologies. Lots of great discoveries are anticipated in these areas which will enhance the biosafety/security levels to unprecedented heights. It should also be noted that in general the volumes required to perform analysis in the micro-fluidic devices usually range from a few microliters to hundreds of microliters. Volumes larger than these take too long to flow and be processed and hence appropriate macroscale sample preparation, sample cleanup and purification steps are needed to efficiently and reliably couple large samples to micro-fluidic devices.

\section{ACKNOWLEDGMENTS}

The authors are indebted to A. Bhunia, M. Ladisch, J. Paul Robinson, R. Linton and D. Bergstrom, for their collaborations, technical discussions and partnerships on the various previously described projects. The authors also thank the support of a cooperative agreement with the Agricultural Research Service of the U.S. Department of Agriculture, project number 1935-42000035 for the work on bacterial detection.

\section{REFERENCES}

ALI, J.E., SORGER, P.K. and JENSEN, K.F. 2006. Cells on chip. Nature 442, 403-411.

BARNES, J.R., STEPHENSON, R.J., WELLAND, M.E., GERBER, C. and GIMZEWSKI, J.K. 2002. Photothermal spectroscopy with femtojoule sensitivity using a micromechanical device. Nature 372, 79-81.

BASELT, D.R., LEE, G.U. and COLTON, R.J. 1996. Biosensor based on force microscope technology. J. Vac. Sci. Technol., B 14, 789-793.

BASHIR, R. 2004. BioMEMS: State-of-the-art in detection, opportunities and prospects. Adv. Drug Delivery Rev. 56, 1-22. 
BASHIR, R. and WERELY, S. (eds.) 2006. Biomolecular sensing, processing, and analysis. In BioMEMS and Biomedical Nanotechnology, Vol 4, Springer Link, New York, NY.

BASHIR, R., HILT, J.Z., GUPTA, A., ELIBOL, O. and PEPPAS, N.A. 2002. Micromechanical cantilever as an ultra-sensitive $\mathrm{pH}$ micro-sensor. Appl. Phys. Lett. 81(16), 3091-3093.

BELKIN, S. 2003. Microbial whole-cell sensing systems of environmental pollutants. Curr. Opin. Microbiol. 6, 206-212.

BERGER, R., GERBER, C., LANG, H.P. and GIMZEWSKI, J.K. 1996. Micromechanical Sensors: A Road to Femtoscale Science International Conference on Micro- and Nanoengineering "MNE '96," Glasgow, Scotland.

BESTEMAN, K., LEE, J.L., WIERTZ, F.G.M., HEERING, H.A. and DEKKER, C. 2003. Enzyme-coated carbon nanotubes as single-molecule biosensors. Nano Lett. 3, 727-730.

BHATIA, R., DILLEEN, J.W., ATKINSON, A.L. and RAWSON, D.M. 2003. Combined physico-chemical and biological sensing in environmental monitoring. Biosens. Bioelectron. 18, 667-674.

BHATTACHARYA, S., GAO, Y., KORMAPALLY, V., OTHAMAN, M., GRANT, S.A., KLEIBOEKER, S.B., GANGOPADHYAY, K. and GANGOPADHYAY, S. 2006. Mechanics of plasma exposed SOG (spin-onglass) and PDMS (poly dimethyl siloxane) surfaces and their impact on bond strength. Appl. Surf. Sci. 253, 4220-4225.

BINNIG, G., QUATE, C.F. and GERBER, C. 1986. Atomic force microscope. Phys. Rev. Lett. 56, 930-933.

BRAITHEWAITE, A. and SMITH, F.J. 1996. Chromatographic Methods, 5th Ed., Blackie and Academic Professional, London.

BURG, T. and MANALIS, S. 2003. Suspended microchannel resonators for bio-molecular detection. Appl. Phys. Lett. 83, 2698-2701.

BUTT, H.J. 1996. A sensitive method to measure changes in the surface stress of solids. J. Colloid Interface Sci. 180, 251-260.

CANTOR, C.R. and SMITH, C.L. 1999. Genomics: The Science and Technology Behind the Human Genome Project, pp. 120-125, Wiley InterScience Publication, Hoboken, NJ.

CHANG, H., KOSARI, F., ANDREADAKIS, G., ALAM, M.A., VASMATZIS, G. and BASHIR, R. 2004. DNA mediated fluctuations in ionic currents through silicon oxide nanopore channels. Nano Lett. 4, 15511556.

CHEE, G.J., NOMURA, Y. and KARUBE, I. 1999. Biosensor for the estimation of low biochemical oxygen demand. Anal. Chim. Acta 379, 185-191.

CHEN, W.T., HENDRICKSON, R.L., HUANG, C.P., SHERMAN, D., GENG, T., BHUNIA, A.K. and LADISCH, M.R. 2005. Mechanistic 
study of membrane concentration and recovery of Listeria monocytogenes. Biotechnol. Bioeng. 89, 263-273.

CIMINSKA, M.G. 2006. Developing nucleic acid based electrical detection system. Microb. Cell Fact. 5, 1-9.

CLELAND, A.N. and ROUKES, M.L. 1998. A nanometer scale mechanical elastometer. Nature 392, 160-161.

CUI, Y., WEI, Q., PARK, H. and LIEBER, C.M. 2001. Nanowire nanosensors for highly sensitive and selective detection of biological and chemical species. Science 293, 1289-1292.

DAVILA, A., JANG, J., GUPTA, A., WALTER, T., ARONSON, A. and BASHIR, R. 2006. Micro- resonator mass sensors for detection of Bacillus anthracis sterne spores in air and water. Biosens. Bioelectron. Epub ahead of print, doi 10.1016/j.bios.2007.01.012.

DITTRICH, P.S., TACHIKAWA, K. and MANZ, A. 2006. Micro total analysis systems. Latest advancements and trends. Anal. Chem. 78, 3887-3907.

D'SOUZA, S.F. 2001. Microbial biosensors. Biosens. Bioelectron. 16, 337353.

DUFFY, D.C., MCDONALD, J.C., SCHUELLER, O.J.A. and WHITESIDES, G.M. 1998. Rapid prototyping of microfluidic systems in poly(dimethylsiloxane). Anal. Chem. 70, 4974-4984.

ELIBOL, O.H., MORISETTE, D., AKIN, D., DENTON, J.P. and BASHIR, R. 2003. Integrated nano-scale silicon sensors using top-down fabrication. Appl. Phys. Lett. 83(22), 4613-4615.

FERRARI, M. 2006. Biomolecular sensing, processing and analysis. In BioMEMS and Biomedical Nanotechnology, Vol 4, Springer, New York, NY.

FODOR, S.P.A., READ, J.L., PIRRUNG, M.C., STRYER, L., LU, A.T. and SOLAS, D. 1991. Light-directed, spatially addressable parallel chemical synthesis. Science 251, 767-773.

FRITZ, J., BALLER, M.K., LANG, H.P., ROTHUIZEN, H., VETTIGER, P., MEYER, E., GUNTHERODT, H.J., GERBER, C. and GIMZEWSKI, J.K. 2000. Translating biomolecular recognition into nanomechanics. Science 288, 316-318.

FUNG, D.Y.C. 2002. Rapid methods and automation in microbiology, comprehensive reviews in food science and food safety. IFT Electronic Journal 1, 3-22.

GAWAD, S., SCHILD, L. and RENAUD, P. 2001. Micromachined impedance spectroscopy flow cytometer for cell analysis and particle sizing. Lab. Chip 1, 76-82. 
GFELLER, K., NUGAEVA, N. and HEGNER, M. 2005. Micromechanical oscillators as rapid biosensor for the detection of active growth of Escherichia coli. Biosens. Bioelectron. 21, 528-533.

GÓMEZ, R., BASHIR, R. and BHUNIA, A.K. 2002. Microscale electronic detection of bacterial metabolism. Sens. Actuators, B 86, 198-208.

GÓMEZ, R., AKIN, D., BHUNIA, A.K. and BASHIR, R. 2003. Micro-scale impedance based detection of bacterial metabolism. $\mu$ TAS2003/ microTAS2003, Proceedings of the 7th International Conference on Miniaturized Chemical and BioChemical Analysis Systems, Squaw Valley, CA, October 5-9.

GÓMEZ, R., MORISETTE, D. and BASHIR, R. 2005. Impedance microbiology on a chip, microfluidic bioprocessor for impedance microbiology on a chip. J. Microelectromech. S. 14(4), 829-838.

GRAYSON, A.C.R., SHAWGO, R.S., JOHNSON, A.M., FLYNN, N.T., LI, Y., CIMA, M.J. and LANGER, R. 2004. A BioMEMS review: MEMS technology for physiologically integrated devices. Proc. IEEE 92(1), 6-21.

GROISMAN, A. 2005. A microfluidic chemostat for experiments with bacterial and yeast cells. Nat. Methods 2, 685-695.

GUPTA, A., AKIN, D. and BASHIR, R. 2004a. Detection of bacterial cells and antibodies using surface micromachined thin silicon cantilever resonators. J. Vac. Sci. Technol., B 22, 2785-2791.

GUPTA, A., AKIN, D. and BASHIR, R. 2004b. Single virus particle detection using microresonators with nanoscale thickness. Appl. Phys. Lett. 84, 1976-1978.

GUPTA, A., NAIR, P.R., AKIN, D., LADISCH, M.R., BROYLES, S., ALAM, M.A. and BASHIR, R. 2006. Anomalous resonance in a nanomechanical biosensor. Proc. Natl. Acad. Sci. U.S.A. 103, 13362-13367.

HELLER, M.J., FORSTER, A.H. and TU, E. 2000. Active microelectronic chip devices which utilize controlled electrophoretic fields for multiplex DNA hybridization and other genomic applications. Electrophoresis 21, 157-164.

HENRY, A.C., TUTT, T.J., GALLOWAY, M., DAVIDSON, Y.Y., MCWHORTER, C.S., SOPER, S.A. and MCCARLEY, R.L. 2000. Surface modification of poly(methyl methacrylate) used in the fabrication of microanalytical devices. Anal. Chem. 72, 5331-5337.

HILLBORG, H. and GEDDE, U.W. 1998. Hydrophobicity recovery of polydimethyl siloxane after exposure to corona discharges. Polymer 39(10), 1991-1998.

HINTSCHE, R., KRUSE, C.H., UHLIG, A., PAESCHKE, M., LISEC, T., SCHNAKENBERG, U. and WAGNER, B. 1995. Chemical microsensor systems for medical applications in catheters. Sens. Actuators, B Chem. B27, 471-473. 
HOEK, E.M.V. and JAWOR, A. 2002. Nano-filtration separations. Dekker Encyclopedia of Nanoscience and Nanotechnology. Marcel Dekker, Inc., New York, NY.

HU, X., BESSETTE, P.H., QIAN, J., MEINHART, C.D., DAUGHERTY, P.S. and SOH, H.T. 2005. Marker-specific sorting of rare cells using dielectrophoresis. Proc. Natl. Acad. Sci. U.S.A. 102, 15757-15761.

IBRAHIM, M., LOFTS, R., JAHRLING, P., HENCHAL, E., WEEDN, V., NORTHRUP, M. and BELGRADER, P. 1998. Real time microchip PCR for detecting single base differences in viral and human DNA. Anal. Chem. 70, 2013-2017.

ILLIC, B., CZAPLEWSKI, D., ZALALUTDINOV, M., CRAIGHEAD, H.G., NEUZIL, P., CAMPAGLONO, C. and BATT, C. 2001. Single cell detection with micromechanical oscillators. J. Vac. Sci. Technol., B 19, 28252840.

KARUBE, I., TURNER, A.P.F., KARUBE, I. and WILSON, G.S. (eds.) 1992. Biosensors: Fundamentals and Applications, p. 20, Mir Publishers, Moscow, Russia.

KARUNAKARAN, C. and JAYAS, D.S. 2005. Nanotechnology - an emerging technology for use in agricultural and food research. Proceedings of the CSAE/SCGR, paper no. 05-001.

KELLER, U.E.S. 1998.Chemical Sensors and Biosensors for Medical and Biological Applications, Wiley VCH, D-69469 Weinheim, Federal Republic of Germany.

KNOBEL, R.G. and CLELAND, A.N. 2003. Nanometre-scale displacement sensing using a single electron transistor. Nature 424, 291-293.

KOVACS, G.T.A. 1998. Micromachined Transducers Sourcebook, WCB/Mc Graw-Hill, Boston, MA.

KUA, C.H., LAM, Y.C., YANG, C. and TOUMI, K.Y. 2005. Review of bio-particle manipulation using dielectrophoresis. Report on innovation in manufacturing systems and technology. http://hdl.handle.net/1721.1/ 7464 (accessed January 15, 2005).

LAVRIK, N.V. and DATSKOS, P.G. 2003. Femtogram mass detection using photothermally actuated nanomechanical resonators. Appl. Phys. Lett. 82, 2697-2699.

LAVRIK, N.V., SEPANIAK, M.J. and DATSKOS, P.G. 2004. Cantilever transducer as a platform for chemical and biological sensors. Rev. Sci. Instrum. 75(7), 2229-2253.

LAZCKA, O., CAMPO, F.J.D., and MUNOZ, F.X. 2005. Pathogen detection: A perspective of traditional methods and biosensors. Biosens. Bioelectron. 22, 1205-1217.

LEI, Y., CHEN, W. and MULCHANDANI, A. 2006. Microbial biosensors. Anal. Chim. Acta 568, 200-210. 
LI, J., GERSHOW, M., STEIN, D., BRANDIN, E. and GOLOVCHENKO, J.A. 2003. DNA molecules and configurations in a solid state nanopore microscope. Nat. Mater. 2, 611-615.

LINDBERG, D.V., GRIMES, C.A. and GILES, C.L. 2005. Farm-to-table: A situation awareness model for food safety assurance for porous borders. CRFSFS 4, 31-33.

LIU, J. and MATTIASSON, B. 2002. Microbial BOD sensor for waste water analysis. Water Res. 36, 3786-3802.

LONENBERG, R., MAAS, J. and KREUTER, J. 1998. Improved body distribution of 14C-labelled AZT bound to nanoparticles in rats determined by radioluminography. J. Drug Target 5(3), 171-179.

MADOU, M.J. 2002. Fundamentals of Microfabrication: The Science of Minaurization, CRC Press, Boca Raton, FL.

MARTY, J.L., OLIVE, D. and ASANO, Y. 1997. Measurement of BOD: Correlation between 5-day BOD and commercial BOD biosensor values. Environ. Technol. 18, 333-339.

MOULIN, A.M., O'SHEA, S.J. and WELLAND, M.E. 2000. Microcantilever based biosensors. Ultramicroscopy 82, 23-31.

NGUYEN, N.T. and WERELEY, S.T. 2002. Fundamentals and Applications of Microfluidics, Artech House, Boston, MA.

NUGAEVA, N., GFELLER, K., BACKMANN, N., LANG, H., DÜGGELIN, M. and HEGNER, M. 2005. Micromechanical cantilever array sensors for selective fungal immobilization and fast growth detection. Biosens. Bioelectron. 21, 849-856.

PAEGEL, B.M., EMRICH, C.A., WEDEMAYER, G.J., SCHERER, J.R. and MATHIES, R.A. 2002. High throughput DNA sequencing with a microfabricated 96-lane capillary array electrophoresis bioprocessor. Proc. Natl. Acad. Sci. U.S.A. 99, 574-579.

POHL, H.A. 1951. The motion and precipitation of suspensoids in divergent electric fields. J. Appl. Phys. 22, 869-871.

POHL, H.A. 1978. Dielectrophoresis: The Behaviour of Neutral Matter in Nonuniform Electric Fields, Cambridge University Press, Cambridge, UK.

POLLA, D.L., ERDMAN, A.G., ROBINS, W.P., MARKUS, D.T., DIAZDIAZ, J., RIZQ, R., NAM, Y., BRICKNER, H.T., WANG, A. and KRULEVITCH, P. 2000. Microdevices in medicine: Annual review of biomedical engineering. Annu. Rev., 2, 551-576.

PORTEOUS, F., KILLHAM, K. and MEHARG, A. 2000. Chemosphere, Vol 41, pp. 1549-1554, Elsevier, Oxford, UK.

POYARD, S., JAFFREZIC, R.N., MARTELET, C., COSNIER, S. and LABBE, P. 1998. Optimization of an inorganic/bio-organic matrix for the 
development of new glucose biosensor membranes. Anal. Chim. Acta 364, 165-172.

RAITERI, R., NELLES, G., BUTT, H.J., KNOLL, W. and SKLADAL, P. 1999. Sensing of biological substances based on the bending of microfabricated cantilevers. Sens. Actuators, B 61, 213-217.

SALIM, R., WURMUS, A., HARNISCH, A. and HULSENBERG, D. 1997. Microgrippers created in microstructurable glass. Microsystems Technology 4, 32-34.

SANGEETHA, S., SUGANDHI, G., MURUGESAN, M., MADHAV, V.M., BERCHMANS, S., RAJASEKAR, R., RAJASEKAR, S., JEYAKUMAR, D. and RAO, G.P. 1996. Torulopsis candida based sensor for the estimation of biochemical oxygen demand and its evaluation. Electroanalysis 8, 698-701.

SARID, D. 1991. Scanning Force Microscopy. Oxford University Press, New York, NY.

SCHREITER, P.P.Y., GILLOR, O., POST, A., BELKIN, S., SCHMID, R.D. and BACHMANN, T.T. 2001. Physiological characterization of a Synechococcus Sp. (Cyanophyceae) Strain Pcc 7942 iron-dependent bioreporter for freshwater environments. Biosens. Bioelectron. 16, 811-817.

SEKI, A., KAWAKUBO, K., IGA, M. and NOMURA, S. 2003. Microbial assay for tryptophan using silicon-based transducer. Sens. Actuators, B 94, 253-264.

SHI, L., PAOLI, V.D., ROSENZWEIG, N. and ROSENZWEIG, Z. 2006. Synthesis and applications of quantum dots FRET based protease sensor. J. Am. Chem. Soc. 128(32), 10378-10379.

SUBRAMANIUM, A., ODEN, P.I., KENNEL, S.J., JACOBSON, K.B., WARMACK, R.J., THUNDAT, T. and DOKTYCZ, M.J. 2002. Glucose biosensing using an enzyme coated biosensor. Appl. Phys. Lett. 81, 385-387.

THUNDAT, T., ODEN, P.I. and WARMACK, R.J. 1997. Microcantilever sensors. Microscale Thermophys. Eng. 1, 185-199.

TKAC, J., GEMEINER, P., SVITEL, J., BENIKOVSKY, T., STURDIK, E., VALA, V., PETRUS, L. and HRABAROVA, E. 2000. Determination of total sugars in lignocellulose hydrolysate by a mediated Gluconobacter oxydans biosensor. Anal. Chim. Acta 420, 1-7.

TRAN, M.C. 1993. Biosensors, Chapman and Hall and Masson, Paris, France. TRIMMER, W.S. (ed.) 1997. Micromechanics and MEMS: Classic and Seminal Papers to 1990, IEEE Press, Piscataway, NJ.

VOLDMAN, J. 2006. Electrical forces for microscale cell manipulation. Annu. Rev. Biomed. Eng. 8, 425-454.

YAMANA, K., KUMAMOTO, S., NAKANO, H., MATSUO, Y. and SUGIE, Y. 2001. Cyclic voltammetric responses in hybrid formation of 
2'-anthraquinone-modified oligonucleotide with DNA. Chem. Lett. 30, $1132-1133$.

YANG, L., BANADA, P.P., CHATNI, M.R., LIM, K.S., BHUNIA, A.K., LADISCH, M. and BASHIR, R. 2006. A multifunctional micro-fluidic system for dielectrophorectic concentration coupled with immunocapture of low numbers of Listeria monocytogenes. Lab Chip 6, 896-905. YANG, Z., SASAKI, S., KARUBE, I. and SUZUKI, H. 1997. Fabrication of oxygen electrode arrays and their incorporation into sensors for measuring biochemical oxygen demand. Anal. Chim. Acta 357, 41-49. 